\title{
What do social groups have to do with culture?The crucial role of shared experience
}

\section{Bradley W. Bergey* and Avi Kaplan}

Psychological Studies in Education, Temple University, Philadelphia, PA, USA

${ }^{*}$ Correspondence: bradley.bergey@temple.edu

In an eloquent article in a recent volume of American Psychologist, Cohen (2009) evoked a contentious question: what are the boundaries of culture? To Cohen, the extant psychological literature has been too limited in its almost exclusive emphasis on independent-interdependent self-construal as the prime psychological process characterizing cultural variation, with the variation being limited itself to nationalities and an East-West division. Cohen argued that cultural processes are more complex and diverse, and cultural boundaries are more fine-grained. Cohen's apt critique noted that many forms of culture are overlooked when psychologists are so limited in their scope. To expand the conceptual space, Cohen urged psychologists to consider other cultural identities such as religion, socioeconomic status, and regional locale, as well as their possible intersections.

Signifying "cultural" identities that have nominal labels as potential markers for culture may be interpreted to suggest that group membership is synonymous with cultural processes. Cohen's view is more sophisticated than that. However, the emphasis on nominal groupings such as religion and SES - to which we could add race, ethnicity, sexual orientation, disability status, etc. does raise the question: What do these social groups have to do with culture? We argue that a focus on shared meanings of experiences, rather than nominal social groupings, is a more appropriate and productive path toward achieving Cohen's goal of expanding and refining our understanding of culturalpsychological processes.

There are several issues that we believe are pertinent to the relations between social groups and culture. One is the important recognition that all nominal groupings are themselves cultural constructions: social schemas that emerged through social interaction in particular contexts to fulfill conceptual and practical functions in ritualized social life. The meanings of these nominal groupings have very fuzzy boundaries that render group inclusion criteria messy; they change continuously; and they reflect the purposes of those employing the categories more than the characteristics of the group members. Clearly this is the case with the more obviously malleable categories: low SES means quite different things and the category would include people with different economic characteristics depending on the country, the historical period, the political result of deliberations among economists, the purpose of the researchers, and the access to different kinds of data. But, even social categories that in layperson terms have essential properties, such as gender, have previously taken on different meanings and continue to have fuzzy and dynamic boundaries, as is apparent by those whose lifestyles challenge the reification of these labels (e.g., GLBT). As cultural phenomena, nominal groupings should be themselves a topic for study in cultural psychology as they are in other scholarly fields (Brubaker, 2009).

Even more pertinent to the current opinion is the understanding, which not incidentally is shared by Cohen, that each grouping includes people - self-identified or otherwise - who differ in many significant cultural-psychological characteristics and dimensions. By focusing on the nominal group, psychologists are running the risk of over-looking more significant processes; and, clearly, of stereotyping.

This is not to say that group membership has no significance to cultural-psychological processes. Whereas nominal groupings do not have ontological existence, they are an important element in the social-political reality. The cultural-political construction of certain groupings creates experiences that are shared by group members in ways that may, indeed, result in cultural processes. The category of "immigrant" could serve as a case in point. While far from being equalized across all immigrant groups, US immigration policy does treat similarly people who may otherwise share very little with each other (e.g., language, beliefs, values, lifestyles), except for their immigration experience. Similar treatment may result with some shared meaning about the immigration experience. Such shared experiences may manifest, perhaps, in a relieved understanding smile exchanged by two very different people after finishing the lengthy admission process at JFK's INS offices; to borrow from Geertz (1973) - "a speck of behavior, a fleck of culture, and - voilà! - a gesture" (p. 6).

Of course, as Geertz noted, "that... is just the beginning" (p. 6). The prevalent effects of social-political grouping - be they the consequence of formal policy or informal perceptions and norms - may result in collective experiences (e.g., discrimination, differential opportunities, expected behavior), which, in turn, may lead to shared meanings and hence to cultural-psychological processes: cognitive, emotional, motivational, and behavioral manifestations of those shared meanings. These processes clearly merit investigation and intervention.

Yet, it would be a grave mistake to assume a priori that each immigrant to the US or, each attendant to a Christian church, each citizen earning under $\$ 30,000$, each resident of a south-western state - shared the same experiences or made the same meaning of collective experiences. Perhaps the cultural-psychological processes most relevant for understanding these people's actions in particular contexts are rooted in shared experiences that cut across social categories: attending the same public school; commuting during rush hour; relocating after a flood...

There is a seeming tension between understanding that, on the one hand, nominal groupings are dynamic cultural constructions; group members are psychologically and culturally diverse; social group labels, or "cultural" identities, are, in fact, not synonymous with culture; and recognizing on the other hand that despite their nonessentialist nature, group memberships may 
involve common experiences that result in some cultural processes. What may psychologists interested in cultural-psychological processes do?

Oneway to address this challenge is bycareful reflection on the formulation of research questions. Arguably, cultural-psychological processes emerge from and manifest in shared experiences in lived contexts (Cole et al., 1997). Researchers might begin with those lived contexts that play important roles in people's lives and seek the shared meanings of actions in these contexts. Indeed, many cultural psychology researchers already practice such a perspective (e.g., Lawrence et al., 2004; Sherry et al., 2006). In turn, researchers who are interested in the role of the social-political reality of social groups in culture ought to pose research questions with acute sensitivity to social-political-historical processes and should proceed with the awareness that group memberships are cultural constructions and, consequently, political realities rather than reified entities.
Perhaps these conclusions are similar to those Cohen aimed at. We are in full agreement with his challenge to the currently dominant paradigm that focuses on a small number of dimensions generalized across broad nominal categories. However, following many others (e.g., Bruner, 1990; Betancourt and Lopez, 1993; Shweder and Sullivan, 1993), we caution against the emphasis on nominal group labels as the obvious and unproblematic entry point for conceptualizing and investigating culturalpsychological processes.

\section{REFERENCES}

Betancourt, H., and Lopez, S. R. (1993). The study of culture, ethnicity, and race in American psychology. Am. Psychol. 48, 629-637.

Brubaker, R. (2009). Ethnicity, race and nationalism. Annu. Rev. Sociol. 35, 21-42.

Bruner, J. (1990). Acts of Meaning. Cambridge, MA: Harvard University Press.

Cohen, A. B. (2009). Many forms of culture. Am. Psychol. 64, 194-204.

Cole, M., Engeström, Y., and Vasquez, O. A. (1997). Mind, Culture, and Activity: Seminal Papers from the
Laboratory of Comparative Human Cognition. New York: Cambridge University Press.

Geertz, C. (1973). “Thick description: towards an interpretive theory of culture," in The Interpretation of Cultures: Selected Essays, ed. C. Geertz (New York: Basic Books), 3-30.

Lawrence, J. A., Dodds, A. E., and Valsiner, J. (2004). The many faces of everyday life: some challenges to the psychology of cultural practice. Cult. Psychol. 10, 455-476.

Sherry, A., Wood, K., Jackson, E. B., and Kaslow, N. (2006). Racist events and ethnic identity in low income, African Americans. J. Appl. Soc. Psychol. 36, 1365-1380.

Shweder, R. A., and Sullivan, M. (1993). Cultural psychology: who needs it? Annu. Rev. Psychol. 44, 497-523.

Received: 06 October 2010; accepted: 23 October 2010; published online: 18 November 2010.

Citation: Bergey BW and Kaplan A (2010) What do social groups have to do with culture? The crucial role of shared experience. Front. Psychology 1:199. doi: 10.3389/ fpsyg.2010.00199

This article was submitted to Frontiers in Cultural Psychology, a specialty of Frontiers in Psychology.

Copyright $(c) 2010$ Bergey and Kaplan. This is an open-access article subject to an exclusive license agreement between the authors and the Frontiers Research Foundation, which permits unrestricted use, distribution, and reproduction in anymedium, provided the original authors and source are credited. 